\title{
Application of pile foundations in structurally unstable soils
}

\author{
Andrey Alekseev ${ }^{1}$, Pavel Sazonov ${ }^{2}$, Dmitry Zorin ${ }^{2,}$, and Svetlana Vinogradova ${ }^{2}$ \\ ${ }^{1}$ Department of Frozen soil mechanics and foundation analysis, JSC Research Center of Construction, \\ $2^{\text {nd }}$ Institutskaya St, 6, Moscow, 109428, Russia \\ ${ }^{2}$ Research institute of bases and underground structures NIIOSP named after N M Gersevanov, JSC \\ Research Center of Construction, $2^{\text {nd }}$ Institutskaya St, 6, Moscow, 109428, Russia
}

\begin{abstract}
The active development of the Asia-Pacific region is often accompanied by geotechnical problems that require a rational solution. The article presents the results of a laboratory experiment that simulates the process of slurried pile construction in sandy frozen soils. The authors present the dependence of changes in the temperature of the soil and cementsand mortar in time, defined the maximum radius of thawing and the total duration of the process of thawing and freezing back to the natural state, given the recommendations for the design of slurried piles taking into account thermal interaction with permafrost soils. The article presents a laboratory study of the interaction of auger cast piles with frozen soil. The results of laboratory studies of the strength of cement mortars of different compositions, hardened at a negative temperature. Recommendations on the choice of the solution composition for the installation of grout-injected piles in frozen soil are given. The article presents the state of the question of designing multi-blade screw piles, reflects the relevance of the development of methods of calculation and updating the regulatory framework. The authors carried out calculations of the bearing capacity of screw piles on various calculation schemes, the results of which are compared with field tests. As a result of comparison recommendations on the choice of the reliable settlement scheme are given. The authors believe that the solution of the problems identified in the article related to the use of advanced types of pile foundations in difficult geotechnical conditions will significantly improve the reliability of structures, reduce construction time and reduce economic costs.
\end{abstract}

\section{Introduction}

The construction of foundations has always been considered a complex construction task, and in the construction of structures in structurally unstable soils competent choice and calculation of the foundations is the key to trouble-free operation of facilities. In the design of bases and foundations in difficult soil conditions, preference is given to pile foundations. Piles can transmit the loads from the buildings on the solid ground, cutting through weak rocks. When the pile foundations there are some difficulties mainly associated with the laboriousness, but they are more effective than the shallow foundations.

\footnotetext{
* Corresponding author: zorinsved@ mail.ru
} 
The article deals with the problems associated with the construction of pile foundations in structurally unstable soils, such as permafrost soils and their solutions on the example of slurried, auger cast (grout-injected) and screw piles.

\section{Slurried piles}

In connection with the difficulties of pile driving in a sturdy permafrost soils, piles, as a rule, immersed in the well, whose diameter is larger than the largest dimension of the cross section of the pile. Before pile sinking, the well is filled with a mortar in the volume calculated based on the geometrical parameters of the pile and the well, taking into account the filling of the sinus between the well wall and the pile surface with a mortar to the level of seasonal freezing-thawing. Way of pile installation of so called slurried. Typical schemes of the device, requirements and recommendations for drilling wells, filling of the mortar, immersion of piles, as well as for the calculation of the bearing capacity of slurried piles are given in many literature sources, including regulatory [1-4].

Despite the wide spread and study of slurried piles, in modern times there are a number of issues related primarily to the use of cement in the preparation of a solution to fill the sinus between the wall of the well and the pile. Hydration of cement during setting is characterized by heat release. The setting speed is dependent on the ambient temperature. At low temperatures, setting slows down, and at negative - stops. In this regard, the use of cementsand mortar instead of sand or clay mortars increases the time of freezing of the pile in the frozen ground, and accordingly shifts the construction time of the above-ground part of the structure. The solution, which has in its composition cement, more thaws the soil around the well, increasing the radius of thawing frozen soils.

It should be understood that the cement setting occurs only until the freezing of the mortar, therefore, in the case of a small amount of the sinuses, for example, when submerged reinforced concrete pile in a bore with a diameter that is slightly greater than the diagonal piles, and at low values of ground temperature, the mortar freezes relatively quickly, and the hydration of cement occurs. A very different picture is observed when the hollow tubular piles with open lower end are immersed in large-diameter wells drilled in high-temperature soils. In this case, a significant amount of mortar for a long time retains a positive temperature, the heat release of cement during hydration maintains positive temperatures. The period of freezing of the pile into the ground increases, and when the pile fields are arranged, the general temperature of the construction site increases. Restoration of natural temperatures without the use of additional measures to cool the soil will not happen or will be delayed for a long time.

The nature of the thermal interaction of the slurried pile with the surrounding array of frozen soil (temperature, thawing radius, freezing time, the composition of the mortar, the flow and the absence of the process of hydration of cement) directly affects the formation of strength bonds on the contacts of the soil-mortar and the mortar-pile, which determines the bearing capacity of the pile. In SP 25.13330.2012 "Bases and foundations on permafrost soils" presents the values of shear resistance on concrete for clay, sand and lime-sand mortars, for cement-sand mortar, these data are not available.

At present, the issues of thermal and strength interaction of slurried piles with the surrounding frozen soil are studied in NIIOSP named after N. M. Gersevanov. Laboratory tests were carried out to determine the resistance to shear of cement-sand mortar on the freezing surface with a concrete die at different normal pressures (Fig.1,a) and at different temperatures (Fig.1,b), a comparative analysis of the freezing forces of the solution with metal and the resistance to shear of the mortar on frozen soil at different temperatures (Fig.1,c). To study the thermal interaction of a metal pile with a cement-sand mortar in the 
device of a slurried pile, a laboratory experiment was conducted in a cylindrical tray (Fig.1,d and 1,e), the results of which are shown in Fig.1,f.

a)

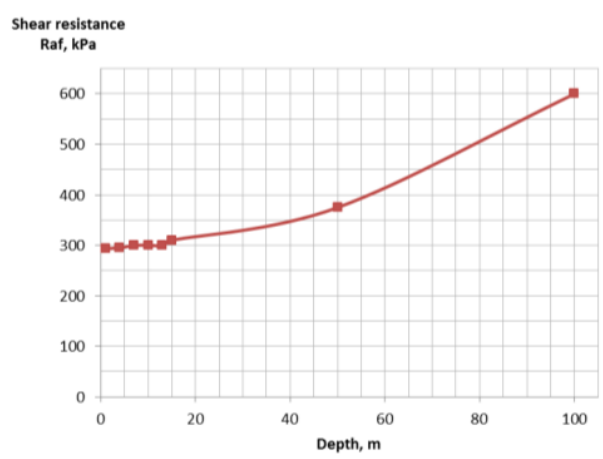

c)

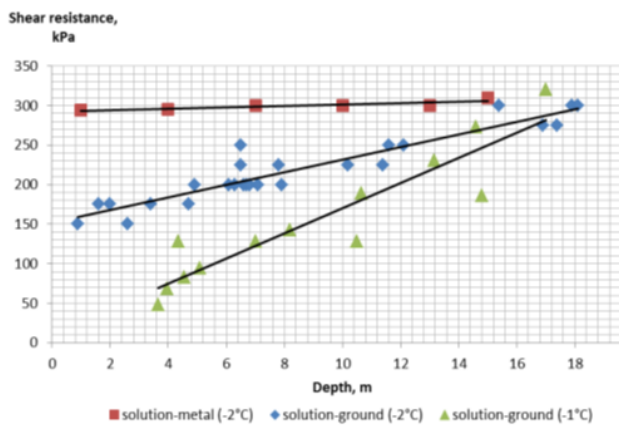

e)

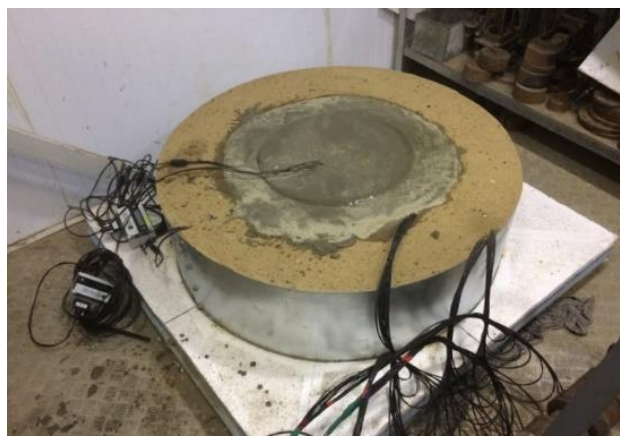

b)

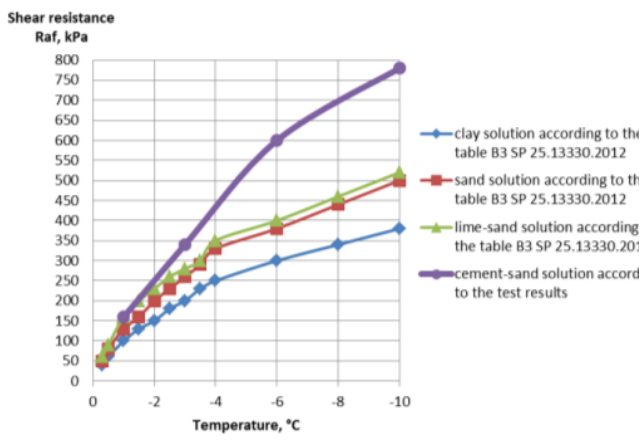

d)

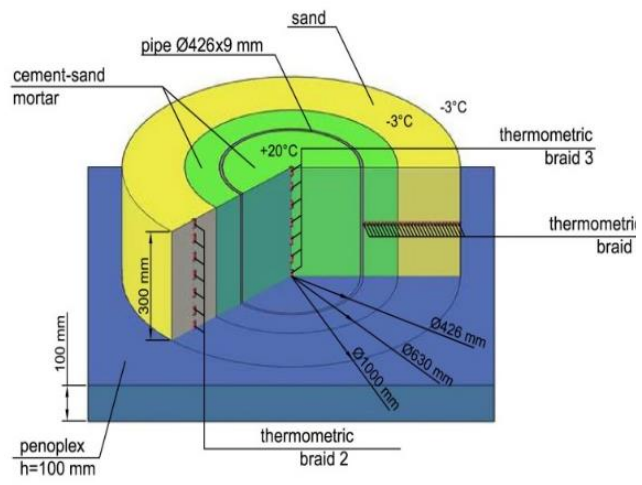

f)

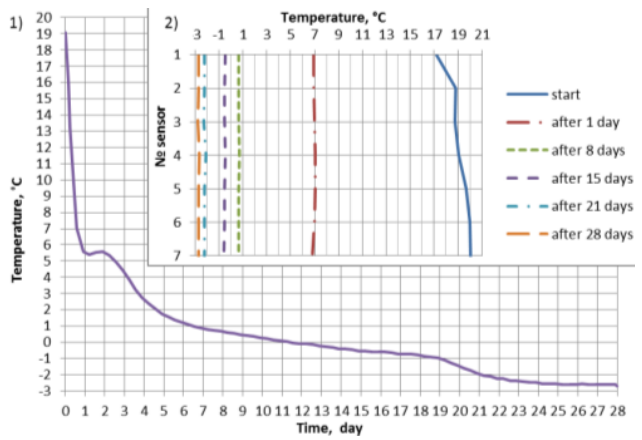

Fig. 1. The results of the research slurried piles. a) graph of the shear resistance in the contact "cement-sand mortar-metal" from the normal pressure at a temperature of minus $2{ }^{\circ} \mathrm{C}$; b) the design resistance of the frozen soil and non-saline mortars of shear on the surface freezing; c) comparison of forces freezing of mortar with the metal and the shear resistance of a mortar for the frozen soil at different temperatures; d) scheme of the cylindrical tray; e) a photo of the tray in the preparation of the experiment; f) graph of the temperature distribution of the mortar over time (1) and in height (2).

As a result of the research it was found:

- the influence of normal load affects the magnitude of the shear resistance on the surface of freezing with the foundation at depths significantly exceeding the depth of immersion of piles, usually equal to $10-15 \mathrm{~m}$; 
- freezing forces of cement-sand mortar with foundation are higher in comparison with clay, sand and lime-sand mortar;

- at a temperature of minus $2^{\circ} \mathrm{C}$, the resistance of the frozen soil to shear along the cementsand mortar is less than the resistance of the cement-sand mortar to shear along the lateral surface of the freezing with pile;

- for piles of steel pipe with a diameter of $426 \mathrm{~mm}$, arranged in permafrost soils with a temperature of minus $3{ }^{\circ} \mathrm{C}$, when filling the cement-sand mortar of the sinus between the wall of the well and the pile, as well as the inner space of the pipe, the freezing time of the pile from filling the mortar at a temperature of $20{ }^{\circ} \mathrm{C}$ to its cooling and freezing to a temperature of minus $3{ }^{\circ} \mathrm{C}$ can be 28 days, the maximum radius of thawing of frozen sand can exceed the radius of the pile by $8 \mathrm{~cm}$.

- when the mortar is cooled, the hydration of cement continues with the release of heat until the water is completely crystallized, which is indicated by the section on the hyperbolic curve of the solution temperature increase by $2{ }^{\circ} \mathrm{C}$ (Fig. 1 , (e).

Currently, when calculating the bearing capacity of piles of structures of normal and reduced levels of responsibility, it is allowed to use the table values of the freezing forces of the lime-sand mortar. The studies found that the cement-sand mortar has higher freezing forces. The bearing capacity calculated in this way is understated, thereby increasing the number of piles or the depth of their immersion, which increases the cost of the foundation.

Accepted in some documents and works [2-4] the time of recovery of the soil temperature, after the installation of slurried piles using the rotational method of drilling ( 5 days), is an understated value. According to the results of the experiment in a cylindrical tray, the duration of freezing of the pile at a soil temperature of minus $3{ }^{\circ} \mathrm{C}$ was 28 days, the freezing of the pile at higher temperatures, obviously, will take even more time. In connection with the threat of disruption of construction time due to the long-term recovery of soil temperature, there is a need for additional measures to cool the soil, which increases the cost of construction. In the design of structures of large size in terms of on the foundation in the form of a pile of fields to calculate the recovery time the design temperature of soil given the bulk of piling. The installation of a large number of slurried piles melts an array of frozen ground, which slows the recovery of natural temperatures and increases the freezing time of the piles.

It should be noted that in the case of construction of linear structures in the area of island distribution of permafrost soils for the unification of equipment for the device of foundations, it is advisable to use slurried piles both on sites of frozen and on sites of thawed soils. Experience in the use of slurried tubular piles in thawed soils is absent, therefore, it is necessary to study both the technology of their manufacture (the device in the presence of groundwater, in unstable soils and in winter), and the calculations of such piles.

\section{Auger cast (grout-injected) piles}

The development of new and adaptation of existing types of piles for structurally unstable soils expands the arsenal of tools for the selection of optimal technological and design solutions for foundations. Therefore, in complex geotechnical conditions, such as permafrost, it may be appropriate to use auger cast piles. This can lead to a significant reduction in the cost of pile foundation by using cheaper monolithic concrete instead of steel or reinforced concrete elements of factory production.

Auger cast piles are considered to be all pile structures, for which it is necessary to apply pre-drilling and subsequent process of concreting. The manufacturing technology has a large number of variations, each of which is shown for application to specific conditions. This method has found wide use in the installation of the foundations for the bridge supports and high-load constructions on not frozen (thawed) soil. 
In the cryolithozone piles, arranged by the auger cast method, are currently practically not used, despite the fact that the first studies of their work in the frozen ground were carried out in the early 40s [7]. The current normative and technical document in Russia SP 25.13330.2012 [1] in the field of foundation in permafrost does not recommend the use of auger cast piles and has no requirements for their design. It is believed that when their device in the frozen ground is transmitted a significant amount of heat.

It is also common to refer to auger cast piles and grout-injected piles, which are more flexible $(1 / \mathrm{d}=80-120)$ and small diameter $(\mathrm{d}=120-250 \mathrm{~mm})$, and are used mainly to strengthen existing foundations and anchorages [8]. Now in the cities located in the cryolithozone, construction is increasingly being carried out near the existing building. At the same time, the construction of a new facility has not only a mechanical effect on the foundations of the existing building, but also a strong thermal effect, which in turn leads to thawing of the foundation soils. The use of grout-injected piles in the northern regions will reduce these effects on the foundations of existing structures while strengthening them due to their smaller size compared to slurried and auger cast piles.

The installation of grout-injected piles in permafrost can assume the admission of freezing of their cement body, as well as ensuring its hardening through the use of chemical additives or heating. As part of the study of this issue in NIIOSP named after N. M. Gersevanov, carried out laboratory experiments to determine the nature of the interaction hardening of cement with frozen soil at the installation of grout-injected piles [9].

The aim of the study is to determine the possibility of hardening cement mortar in contact with frozen soils, to obtain experimental data on the strength of cement stone, resistance to shear on the surface of its freezing with the ground and the total bearing capacity of groutinjected piles in permafrost. One of the main tasks to be solved during the study was to determine the necessary composition of cement mortar with an admixture of chemical additives to ensure its hardening at negative temperatures. Intermediate results of laboratory experiments and literature analysis devoted to this problem are given in this article.

According to the research of the Institute of permafrost [10] hardening of cement in conditions of negative temperatures of the cement test and the environment is possible only if the liquid phase (water) in the cement mortar is provided. The mortar, in conditions of negative temperatures, should have sufficient: the duration of thickening, spreadability (fluidity), setting time, mechanical strength and intensity of hardening. The recommendations on the concreting of foundations in permafrost soils of the NIIZHB Gosstroy of the USSR give the possible types and number of additives applied to the installation of auger cast piles as a whole.

In addition, the hydration of mortars in contact with the frozen soil depends on many different factors, such as volume, temperature, composition of the mortar, etc. when the installation of grout-injected piles in contrast to the auger cast uses a much smaller amount of mortar, the concrete mixture is replaced with a cement mortar in consequence of which the required types and quantities of additives are changed to ensure hardening.

Tests to determine the strength of the cement stone, hardened at negative temperatures, were carried out on samples (cubes) of nominal sizes $70 \times 70 \times 70$. The water-cement ratio of the mortars was taken taking into account the technological features of the device of groutinjected piles $-\mathrm{W} / \mathrm{C}$ from 0.34 to 0.4 . Cement mortar was produced at a temperature of 20 ${ }^{\circ} \mathrm{C}$, thoroughly mixed and transferred to the freezer, where it was poured into molds. The temperature in the chambers ranged from minus 1 to minus $3{ }^{\circ} \mathrm{C}$ for different test series. The strength of the cement stone was determined for cubes with a hardening time of 7, 14 and 28 days.

Data on the composition of cement mortars with admixture of chemical additives and the results of compression tests are given in table 1 . 
Table 1. Strength of cement cubes at negative temperature.

\begin{tabular}{|c|c|c|c|c|c|c|}
\hline $\begin{array}{l}\text { Number } \\
\text { of } \\
\text { mortar }\end{array}$ & $\begin{array}{c}\text { Cement } \\
\text { brand }\end{array}$ & $\begin{array}{l}\mathrm{W} / \mathrm{C} \\
\text { ratio }\end{array}$ & $\begin{array}{l}\text { Additives in cement, in } \\
\% \text { of the cement mass }\end{array}$ & $\begin{array}{c}\text { Hardening } \\
\text { temperature } \\
{ }^{\circ} \mathrm{C}\end{array}$ & $\begin{array}{l}\text { Hardening } \\
\text { time, day }\end{array}$ & $\begin{array}{l}\text { Strengt } \\
\mathrm{h}, \mathrm{MPa}\end{array}$ \\
\hline 1 & \multirow{7}{*}{$\begin{array}{l}500, \\
\text { strength } \\
50 \mathrm{MPa}\end{array}$} & \multirow{5}{*}{0,4} & - & \multirow{3}{*}{ minus 3} & 7 & 3.5 \\
\hline 2 & & & - & & 28 & 4.1 \\
\hline 3 & & & $\begin{array}{l}1 \% \text { - complex additive } \\
\text { based plasticizer and } \\
\text { antifreeze components }\end{array}$ & & 28 & 5.9 \\
\hline 4 & & & - & \multirow{4}{*}{ minus 1} & 28 & 6,6 \\
\hline 5 & & & $\begin{array}{l}3 \% \text { - complex additive } \\
\text { based plasticizer and } \\
\text { antifreeze components }\end{array}$ & & 28 & 10,0 \\
\hline 6 & & \multirow{2}{*}{0,34} & $\begin{array}{l}3 \% \text { - complex anti-frost } \\
\text { additive based on } \\
\text { naphthalene sulphonate } \\
\text { and alkali metal salts }\end{array}$ & & 14 & 11,5 \\
\hline 7 & & & $\begin{array}{l}3 \% \text { - sodium formate; } \\
0.7 \% \text { - naphthalene } \\
\text { formaldehyde } \\
\text { superplasticizer }\end{array}$ & & 14 & 13,0 \\
\hline
\end{tabular}

Analysis of the test results showed that the strength of the cement stone, defined for cubes with a hardening time of 7 and 28 days, solidified at a negative temperature of minus $3{ }^{\circ} \mathrm{C}$ was 3.5 $\mathrm{MPa}$ and 4.1 $\mathrm{MPa}$, respectively. These values range from 6.3 to $8.2 \%$ of the brand strength of cement. It should be noted that for 7 to 28 days the strength of cement stone increased, though not significantly. This indicates the presence in the frozen solution of unfrozen chemically bound water at the selected test temperature (minus $3{ }^{\circ} \mathrm{C}$ ) and the duration of the hydration process. The strength gained by the cement cubes at a temperature of minus $1{ }^{\circ} \mathrm{C}$ exceeds that obtained at minus $3{ }^{\circ} \mathrm{C}$ by almost $25 \%$ and is equal to $6.6 \mathrm{MPa}$ for a hardening time of 28 days.

The results of the use of chemical anti-frost additives in cement, hardened at a temperature of minus $3{ }^{\circ} \mathrm{C}$ showed that the strength of the cement stone is not significantly increased. Mortar №3 showed an increase in strength by $40 \%$ compared to conventional cement W/C 0.4 , solidified 28 days and was $11.8 \%$ compared to the brand strength. The most satisfactory result at the moment was obtained at a hardening temperature of minus $1{ }^{\circ} \mathrm{C}$. Mortars $5-7$ scored from 20 to $26 \%$ of the brand strength and from 50 to $100 \%$ of the strength gained by conventional cement at the same temperature.

On the basis of the data obtained, it can be concluded that the strength of cement stone at negative temperatures can be achieved by mixing cement with an aqueous mortar of certain salts in the required ratio even with a relatively small volume used in the device of groutinjected piles.

Addition in cement composition of these solutions should provide:

- frost-free mortar at negative temperature (the desired temperature of the freezing);

- preservation of mobility (fluidity) of cement mortar during the necessary time for its injection into the annular space;

- sufficient setting time at negative temperatures, strength and intensity of hardening;

- weak aggressiveness towards contact materials;

- the necessary value of the shear resistance on the surfaces of freezing cement stone with frozen soil and reinforcing elements. 
The formulation of the mortar should be installed depending on the temperature of the frozen soil and the ambient air, as well as the properties of the cement.

Selection of the mortar composition, hardening in contact with permafrost soil, can be made in any proven way, ensuring compliance with the requirements for the mixture of mobility, air content, non-dispersibility, as well as to the cement stone for strength, frost resistance, resistance in an aggressive environment and water resistance at the minimum for these fillers costs of cement and water.

Also, the selection of mortar compositions should take into account the geocryological conditions of the construction site, thermal properties and temperature of the bases. For hightemperature soils, the amount of chemical additives based on salts should be correspondingly less in percentage ratio than for low-temperature soils.

The strength set of cement, hardening at low temperatures at the installation of auger cast and grout-injected piles in permafrost, is one of the main tasks that need to be solved for their further application in the cryolithozone.

\section{Screw piles}

Along with slurried and grout-injected piles, the construction of the pile oundation of screw piles is actively gaining popularity. Screw piles are a steel barrel with one or more blades and are immersed in the ground by screwing. The screw piles are immersed using hydraulic motors installed on the construction equipment with hydraulic drive. Screw piles work effectively on horizontal and pulling loads, and are widely used as foundations of supports of linear structures. During the construction of oil and gas pipelines of long length, soil conditions may include thawed, structurally unstable, permafrost soils, etc. May be difficult to access and difficult to pass for the overall technology of landscapes, which leads to the complexity and increase in the cost of construction. In these cases, it is important to use screw piles.

Available manufacturing and immersion technologies, absence of earthworks and" wet processes", in contrast to slurried and grout-injected piles, minimal disturbance of the soil structure during screwing determine the prospects of using screw piles in any ground conditions, except rock. But despite the advantages of using screw piles, there are limitations caused by the lack of standardized methods of their calculation. In the main document on design of pile foundations in Russia SP 24.13330.2011 included a method of calculation of single-blade screw piles, with some restrictions: the diameter of the blade is not more than $1.2 \mathrm{~m}$, and the length of the pile barrel is not more than $10 \mathrm{~m}$, when the depth in the ground is not less than 5D in clay soil and 6D - in sand, due to the empirical nature of the technique.

To eliminate the existing gaps in the regulatory framework, it is necessary to create an actual method of calculating the bearing capacity and deformation of multi-blade screw piles. The ways of solving the problem are considered in the article, and represent a set of measures, including statistical processing of data of field and tray tests of screw piles by pressing, pulling and horizontal load in various ground conditions. As well as their subsequent mathematical modeling using proven geotechnical calculation systems and the study of existing domestic and foreign analytical calculation methods.

This article presents the results of calculations of multi-blade screw piles on the action of the pressing load by three different methods. The first and second methods of the SP 24.13330.2011 (the method of "Screw pile" p. 7.2.10 and the technique of "Pile with broadening" p. p. 7.2.6-7.2.9). The third is the "Canadian method" proposed by Narasimha et al., for the design of screw piles in cohesive soils, described in more detail in article. For each technique, figure 2 shows the calculation scheme for determining the bearing capacity of the pile. To assess the adequacy of the results obtained, their comparison with the results of numerical studies in Plaxis 2D and with experimental data of field tests. 
The object of the study was a pile field of multi-blade screw piles, arranged in the construction of petrochemical complex "ZapSib-2" in Tobolsk, Tyumen region. The soil conditions of the construction site are presented in table 2, for research purposes, normative values of soil characteristics were used in the calculations.

Table 2. Normative characteristics of soils.

\begin{tabular}{|c|c|c|c|c|c|c|c|c|c|c|}
\hline $\begin{array}{c}\mathrm{Nu} \\
\mathrm{mb} \\
\mathrm{er}\end{array}$ & Soil: loam & $\begin{array}{c}\mathrm{W}, \\
\%\end{array}$ & $\begin{array}{c}\gamma, \\
\mathrm{kN} / \\
\mathrm{m}^{3}\end{array}$ & e, u.s & $\begin{array}{c}\mathrm{I}_{\mathrm{p}}, \\
\text { u.s }\end{array}$ & $\begin{array}{c}\mathrm{I},, \\
\text { u.s }\end{array}$ & $\begin{array}{c}\mathrm{c}, \\
\mathrm{kPa}\end{array}$ & $\begin{array}{c}\varphi, \\
\text { degr } \\
\text { ee }\end{array}$ & $\begin{array}{c}\mathrm{E}, \\
\mathrm{MPa}\end{array}$ & $\begin{array}{c}\mathrm{v}, \\
\text { u.s }\end{array}$ \\
\hline 6a & semisolid & 26 & 18.9 & 0.82 & 0.13 & 0.13 & 25 & 22 & 15.5 & 0.35 \\
\hline 6b & refractory & 28 & 19.0 & 0.84 & 0.12 & 0.37 & 18 & 19 & 12.0 & 0.36 \\
\hline 6c & soft plastic & 30 & 18.5 & 0.92 & 0.11 & 0.61 & 14 & 16 & 8.0 & 0.37 \\
\hline
\end{tabular}

Field tests of piles at the site were carried out by the staff of NIIOSP named after N. M. Gersevanov, JSC "RC Construction" in accordance with State standard 5686-2012 in accordance with paragraph 8 and annexes $\mathrm{K}$ and $\mathrm{L}$, the results presented in figure 3, relative to the results of numerical calculations in Plaxis $2 \mathrm{D}$.

The pile field is represented by multi-blade screw piles of four sizes, the characteristics of which are presented in table 3 .

Table 3. Sizes of experienced multi-blade screw piles.

\begin{tabular}{|c|c|c|c|c|c|c|c|c|}
\hline \multirow{2}{*}{$\begin{array}{c}\text { Num } \\
\text { ber }\end{array}$} & \multirow{2}{*}{ Multi-blade screw pile } & \multicolumn{7}{|c|}{ Parameters } \\
\cline { 3 - 10 } & & $\begin{array}{c}\mathrm{d}, \\
\mathrm{mm}\end{array}$ & $\begin{array}{c}\delta, \\
\mathrm{mm}\end{array}$ & $1, \mathrm{~m}$ & $\begin{array}{c}\mathrm{h}, \\
\mathrm{mm}\end{array}$ & $\begin{array}{c}\mathrm{D}, \\
\mathrm{mm}\end{array}$ & $\begin{array}{c}\mathrm{n}, \\
\text { unit }\end{array}$ & $\Delta, \mathrm{mm}$ \\
\hline 1 & $89 \times 6-5500-\mathrm{R} 10-260 / 260 / 260$ & 89 & 6 & 5.5 & 10 & 260 & 3 & 780 \\
\hline 2 & $114 \times 8-5500-\mathrm{R} 16-340-340-340$ & 114 & 8 & 5.5 & 16 & 340 & 3 & 1020 \\
\hline 3 & $159 \times 8-11000-\mathrm{R} 16-470-470-470$ & 159 & 8 & 11.0 & 16 & 470 & 3 & 1410 \\
\hline 4 & $219 \times 8-11000-\mathrm{R} 16-450-450$ & 219 & 8 & 11.0 & 16 & 450 & 2 & 1950 \\
\hline
\end{tabular}

Notes: $\mathrm{d}$ - shaft diameter; $\delta$ - wall thickness of the shaft; 1 - working (submerged soil) pile depth; $\mathrm{h}$ - thickness of the blade; $\mathrm{D}$ - the diameter of the blades; $\mathrm{n}$ - number of blades; $\Delta$ - the distance between the blades. 


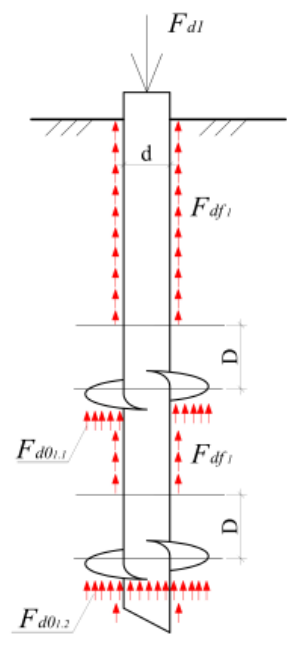

a)

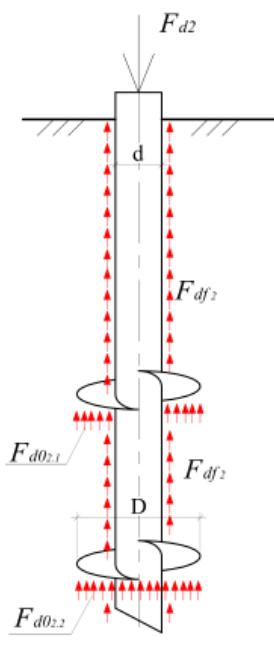

b)

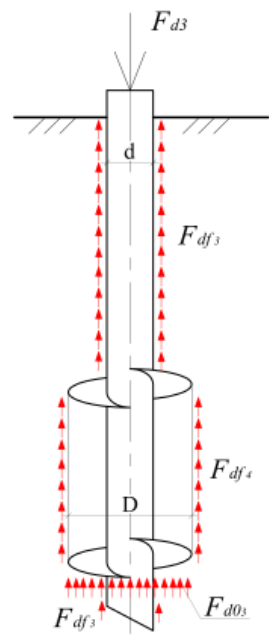

c)

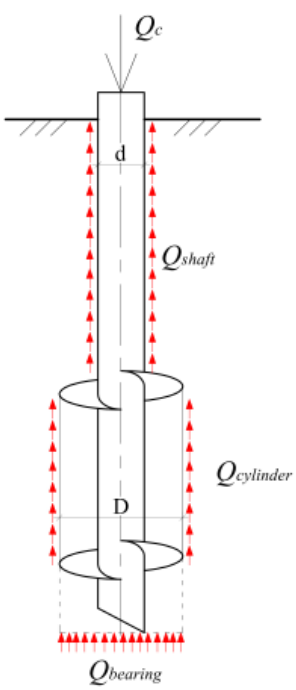

d)

Fig. 2. Design schemes for determining the bearing capacity of the pile under compressive load. a) by the method of "Screw pile"; b) by the method of "Pile with broadening"; c) by the method of "Combined method" Canadian method with broadening; d) by the "Canadian method".

Further, numerical simulation of piles in the Plaxis 2D software complex was carried out using the Coulomb-Mora elastic-plastic model. The results of numerical studies and field tests were considered when moving piles at $40 \mathrm{~mm}$. At the end of mathematical modeling were obtained the results of the overall bearing capacity is relatively similar to the results of the field test, the maximum difference is oriented in the direction of understating the calculation of the resistance of the pile and has not exceeded $30 \%$.

Analytical results of the calculation of the total bearing capacity of piles by different methods were considered with respect to the results of numerical calculations in Plaxis 2D. Comparison of the test data and the results of analytical calculations of the total bearing capacity relative to the bearing capacity, adopted according to mathematical modeling are shown in figure 3.

Two basic approaches were used for analytical calculations of the bearing capacity under the blades of screw piles. In the first approach, the bearing capacity under the blades of the piles was calculated as the sum of the ground drag on contact with each blade. The approach is taken into account in the technique of "Screw pile" and "Pile with broadening". In the second - the drag was taken into account for one (the first in the direction of movement) of the blade, and between the blades was taken the vertical shear resistance of the soil on the side surface of the cylinder with the diameter of the blades of the piles. The approach is taken into account in the "Canadian technique" method and in the combined "Canadian technique with broadening" method.

Analysing the data obtained, we distinguish two distinctive features of the results:

First, at values of $8<H / D \leq 14$, where $D$ is the diameter of the blade, and $H$ is the depth to the upper blade, all considered methods showed fairly accurate results with a maximum deviation of not more than $10 \%$, excluding the combined method "Combined technique". But the technique of "Pile with broadening" showed more reliable results. 


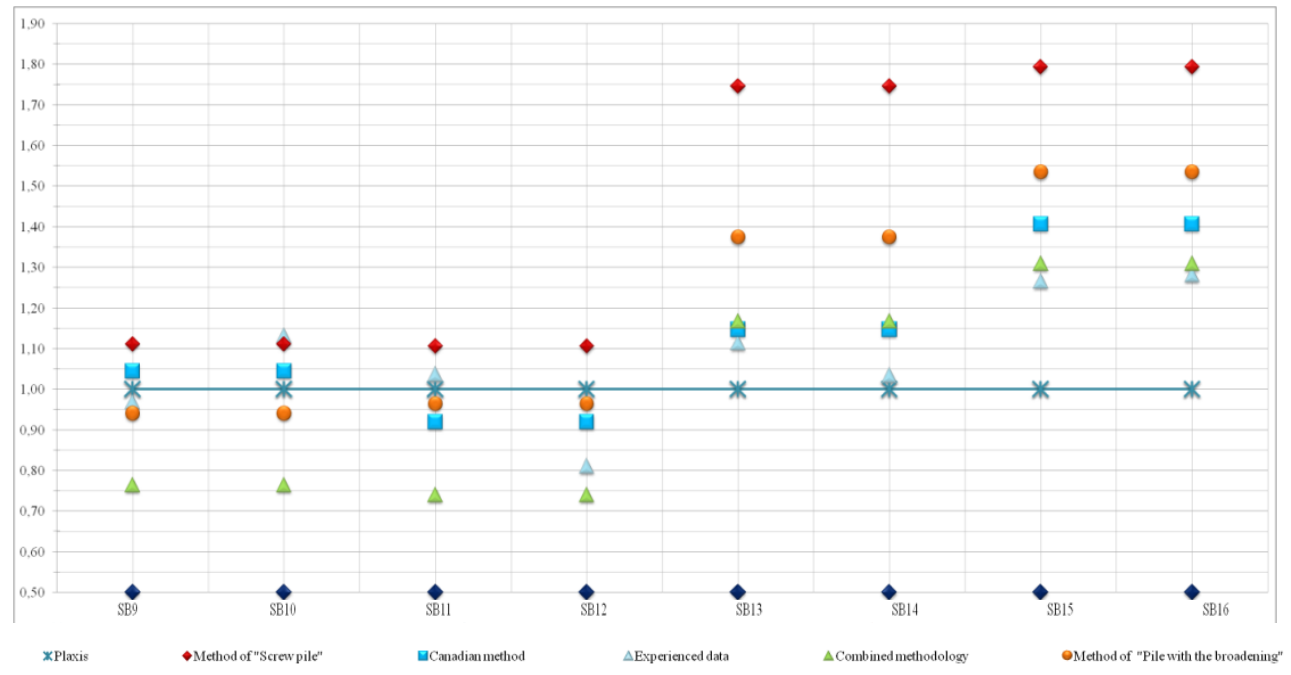

Fig. 3. Comparison of the calculation results of the total bearing capacity under the action of a compressive load.

Second, at $15<\mathrm{H} / \mathrm{D} \leq 19$, the diagram shows that the second drag approach described above is implemented here. The method of "Screw pile" and "Pile with broadening", taking into account the drag under each blade, give too high results, with a maximum deviation of $80 \%$. In conclusion, if we evaluate the results of the calculation of the bearing capacity of all piles, "Canadian technique" showed the best correlation with the data of field tests and the results of numerical simulation.

However, a comparative analysis of the total bearing capacity of multi-blade screw piles can give only an approximate picture of the physics of the process of pile operation. For a more detailed study and evaluation of the calculation methods, it is necessary to consider separately the bearing capacity on the side surface and the drag under the blades and their ratios. Further research and testing of various types of piles will give more information to create an actual method for calculating the bearing capacity of multi-screw piles, which will be based either on the existing with subsequent revision, or on the foreign method adapted to Russian standards.

\section{Conclusions}

Summing up, we note that the relevance of studying the questions of technology of the device and methods of calculation slurried, auger cast (grout-injected) and screw piles is not in doubt. In the context of the rapid pace of construction of facilities in the areas of distribution of structurally unstable, including permafrost soils, the issues of reducing the construction time of the foundation, ensuring its reliability, high bearing capacity and simplifying the technology of work require due attention and discussion.

\section{References}

1. Russian State Standard SP 25.13330.2012 Bases and foundations on permafrost soils

2. L. N. Khrustalev, Fundamentals of geotechnics in cryolitozone (MSU, Moscow, 2005)

3. Yu. M. Goncharov, Yu. O. Targulyan, S. H. Vartanov, The manufacture of pile works on the permafrost (Stroizdat, Moscow,1981) 
4. Recommendations for pile foundations in permafrost soils (NIIOSP named after N. M. Gersevanov, Moscow, 1985)

5. Recommendations for concreting foundations and communications in permafrost taking into account the hardening of concrete at low temperatures (NIIZHB Gosstroy, Moscow, 1982)

6. Russian State Standard 10180-2012 Concrete. Methods for determining the strength of the control samples

7. Russian State Standard SP 24.13330.2011 Pile foundations

8. State Standard 5686-2012 Soils. Methods of field tests by piles

9. Yu. G. Trofimenkov, L. G. Mariupol, Screw piles as foundations of masts and towers of transmission lines (OFMG, 1964)

10. Special technical conditions. On design with application of multi-blade steel screw piles SINTEK of the bases of buildings of the West Siberian complex of deep processing of hydrocarbon raw materials (UVS), (JSC RC Construction, Moscow, 2014) 